\title{
Biological evaluation of the weight reduction capacity of selected herbal products available in the Kingdom of Saudi Arabia
}

\author{
Nora Abdullah Al-Faris \\ Nutrition and food science, Princess Nourah bint Abdulrahman University, Riyadh, Kingdom of Saudi Arabia \\ Email address: \\ naalfaris@pnu.edu.sa (N. A. Al-Faris)
}

\section{To cite this article:}

Nora Abdullah Al-Faris. Biological Evaluation of the Weight Reduction Capacity of Selected Herbal Products Available in the Kingdom of Saudi Arabia. International Journal of Nutrition and Food Sciences. Vol. 3, No. 1, 2014, pp. 7-13. doi: 10.11648/j.ijnfs.20140301.12

\begin{abstract}
Herbal products are often marketed for weight reduction in the Kingdom Saudi Arabia, this study aimed to evaluate weight loss claims and safety of three popular herbal products marketed in Riyadh, Albino rats aged 6-7 weeks were fed a diet comprising 15\% mixed herbal products and compared with controls, any changes in weight and food intake were recorded. Haemogram, lipid profile and renal and liver function tests were conducted, compared with the control group, the body weight of rats significantly decreased when fed with two herbal products that contain high percentage of caffeine. Weight and food intake non-significantly increased in one group, there were minimal or no significant differences in the haematological and biochemical profiles, herbal products containing senna, sage, cumin and ginger may have beneficial value in managing obesity most likely because of the high content of caffeine. Further studies are necessary in order to confirm this supposition.
\end{abstract}

Keywords: Biochemical Profiles, Caffeine, Haematological Profile, KSA, Lipid, Rat, Weight Reduction

\section{Introduction}

Obesity is a social problem with established links to adverse health outcomes, such as hypertension, hyperlipidaemia and insulin resistance. As reported by World Health Organization [1], at least 2.8 million adults die annually because of being overweight or obese. Thus, health organizations are giving significant attention to this problem. Recent studies have revealed that the number of overweight and obese people in the Kingdom of Saudi Arabia (KSA) have dramatically increased over the past few decades; $42.4 \%$ of males and $31.8 \%$ of females are overweight, whereas $26.4 \%$ and $44.0 \%$, respectively, are obese [2].

Although a balanced diet and exercise are the recommended methods for controlling body weight [1], people often turn to herbal products to prevent diseases, such as cardiovascular and musculoskeletal ailments, and to promote health and well-being, for example stress reduction and weight loss [3]. Nowadays a trend where the consumption of herbal products is on the increase is evident in both developing and developed countries [4]. Rates [5] outlines alternative medicines and drugs marketed as neutral compounds. However, this does not mean that they are free from side effects [6]. Some may even be contaminated with metals, or adulterated with synthetic drugs [4], thereby placing consumers at risk.

Although some alternative therapies may initially reduce weight, several have unproven efficacy and may lead to serious problems [7]. Green tea is an example of a product marketed for weight loss without supposed harmful side effects. However, studies have shown that there are. For example, Chan et al [8] investigated the impact of green tea on body weight, biochemistry and hormone profiles of 34 obese Chinese women and found that although the women lost weight as compared to controls, green tea led to a significant increase in their triglyceride level. In a systematic review on the use of herbs for weight loss, Pitter et al. [9] concluded that although some herbs were effective for weight loss if linked to dietary changes, many had no effect on weight control-their impact resulted from materials that affect either the volume of food intake or energy balance. A study by Steffen et al. [10] found that $64 \%$ participants had used alternative products to reduce weight with an average monthly expenditure of $33.88 \pm$ 41.1 USD. In addition, $62.3 \%$ of participants had side effects from using of these products. Information about 
these products was obtained from popular media. Magazines counted for $38.3 \%$ of such cases.

Alternative medicine use in the KSA is high. In one cross-sectional survey of residents in the Riyadh region, $68 \%$ of the participants had used alternative medicine in the previous 12 months [11]. Highlighting the issue of contamination and potential toxicity of herbal products, [4] found that eight remedies marketed in the KSA contained synthetic drugs e.g. benzodiazepines and tricyclic antidepressants (in sedative doses) and cyproheptadine. Furthermore, Al Majed et al. [12] found that the herbal supplements in KSA contained factors that may either enhance or diminish the appetite and moreover, adversely affect the nervous system.

There is a paucity of data on the effects of herbal products marketed in KSA for weight loss, particularly with respect to their efficacy and their impact on lipid and haematological profiles. Therefore, the present study aimed to evaluate the effects of weight-reducing herbal products marketed in KSA on animal models.

\section{Methods}

\subsection{Selection and Analysis of Herbal Products}

First, data were collected from local vendors regarding the three most popular herbal products with weight reducing claims. These were 'Bent Al Sultan Herbal', 'Lady's Mantle' and 'Dr. Diet'. They are referred to as HP 1, HP 2 and HP 3, respectively. According to its label, Bent Al Sultan Herbal contained Salvia officinalis, Tamarindus indica, Glycyrrhiza glabra, Foeniculum vulgare, Hyssopus officinalis and Cassia angustifolia. Lady's Mantle (Alchemilla Vulgaris) did not have a label. Dr. Diet was produced by Sahara Daubi, but no information on its contents was listed on its label. Subsequently, the approximate chemical compositions of the selected herbal products were obtained using colorimetry, following the guidelines of the Association of Analytical Communities [13]. The content of specifically moisture, ash, protein, fat, mineral, vitamin, caffeine and heavy metals (lead, mercury, arsenic and cadmium) were measured. Shimadzu AA-6800 Atomic absorption spectrophotometer, Shimadzu Scientific Instruments-7102 River wood Drive Columbia MD, 21046, U.S.A, were used. |Microbiological assays were also conducted in order to assess the total viable aerobic bacterial count [14] and weight-reducing medications such as orlistat, sibutramine or steroids [15] using the HPLC system Shimadzu Scientific Instruments-7102 River wood Drive Columbia MD,21046, U.S.A.

\subsection{Subjects}

The appropriate body granted formal ethical approval for this study was nutrition and food science department in Princess Nourah bint Abdulrahman University. Adopting chronic modes, toxicity studies were conducted using 40 male Swiss albino rats aged 6-7 weeks and weighing. The animals were bred and maintained at the Animal House, Central laboratory for Drug and food analysis, ministry of health, Riyadh, Saudi Arabia. The regulatory guidelines on selection of dose for long term treatment require minimal toxicity to allow meaningful evaluation of data [16]. Rats were randomly allotted to control and treatment groups (10 per group), and maintained under standard humidity 50 , temperature $22 \pm 2{ }^{\circ} \mathrm{C}$ and light conditions (12 h each for dark and light).

Table 1. Constituents of control and experimental diets in grams per 100 gram

\begin{tabular}{|c|c|c|c|c|}
\hline \multirow{2}{*}{ Chemical component } & \multicolumn{4}{|c|}{ Quantity of nutrients in per $100 \mathrm{~g}$} \\
\hline & control & Herbal Product 1 & Herbal Product 2 & Herbal Product 3 \\
\hline Cornstarch & 46.57 & 39.58 & 39.58 & 39.58 \\
\hline Casein & 14.00 & 14.00 & 14.00 & 14.00 \\
\hline Dextrinised cornstarch & 15.50 & 15.50 & 15.50 & 15.50 \\
\hline Sucrose & 10.00 & 10.00 & 10.00 & 10.00 \\
\hline Soybean oil & 4.00 & 4.00 & 4.00 & 4.00 \\
\hline Fibre & 5.00 & 5.00 & 5.00 & 5.00 \\
\hline Mineral mix & 3.50 & 3.50 & 3.50 & 3.50 \\
\hline Vitamin mix & 1.00 & 1.00 & 1.00 & 1.00 \\
\hline L-Cystine & 0.18 & 0.18 & 0.18 & 0.18 \\
\hline Choline bitartrate & 0.25 & 0.25 & 0.25 & 0.25 \\
\hline Mixture ( $15 \%$ carbohydrate) & - & 6.99 & 6.99 & 6.99 \\
\hline Total & 100.00 & 100.00 & 100.00 & 100.00 \\
\hline
\end{tabular}

Key: HP 1 Bent Al Sultan Herbal, HP 2 Lady’s Mantle and HP 3 Dr. Diet

All animals were given free access to water. The control group were fed ad libitum with a Purina ${ }^{\circledR}$ chow diet was purchased from the Arabian Agricultural Services Company (Arasco), Riyadh, Saudi Arabia The feeds given to the experimental groups were prepared according to the American Institute of Nutrition (AIN) guidelines [17]. Dose selection was based on the regulatory guidelines requiring minimal toxicity during long-term treatment [16]. As body 
weight and water intake increased over time, the daily dose was adjusted to approximate the initial human therapeutic dose specified by the manufacturer. The herbal products were ground and mixed with standard pellets so that the feed contained $15 \%$ of carbohydrate weight replacement with herbal products and the feed was stored at $5^{\circ} \mathrm{C}$ until used. Table 1 summarises the control and experimental diets. The diets containing HP 1, HP 2 and HP 3, were labelled as $\mathrm{T} 1, \mathrm{~T} 2$ and $\mathrm{T} 3$, respectively.

\subsection{Parameters Assessed}

\subsubsection{Assessment of Toxicity}

As suggested by the WHO scientific group [18] and Mossberg and Hayes [16].

\subsubsection{Assessment of Weight Change}

The body weights were recorded before and after the experimental period to examine the impact of the different drugs on body weight. Furthermore, at the end of the treatment, the weights of the vital organs (heart, lungs, kidney, spleen, liver and testes) were weighed and reported per $100 \mathrm{~g}$ body weight to facilitate comparison between normal and control animals.

\subsubsection{Haematological and Biochemical Analysis}

These were assessed before and after the experimental period. The haematological profiles included the white blood cell count (WBC), red blood cell count (RBC), haemoglobin $(\mathrm{Hb})$, haematocrit $(\mathrm{HCT})$ and the mean corpuscular volume (MCV). Blood was also collected and the serum separated and stored at $-20^{\circ} \mathrm{C}$, for later biochemical analysis of liver and kidney function and lipid profile. Specifically, alanine aminotransferase (ALT) aspartate aminotransferase (AST) [19]; glucose [20]; urea [21]; creatinine [22]; cholesterol; triglycerides [23]; high density lipoprotein (HDL) cholesterol [24] and low-density lipoprotein (LDL) cholesterol [25]. The parameters were analysed by an enzymatic colorimetry using test combination reagents (Boehringer Mannheim GmbH, Diagnostica, Germany). Measurements were made using a spectrophotometer (Introspect II, LKB).

\subsection{Statistical Analysis}

Statistical analysis was performed using SPSS v.15 (Statistical package for social sciences, version 15, SPSS Inc, Chicago, USA). The student's t-test and chi-square test were used to assess the significance of the values obtained in both the treated and the control groups during the study. $P$ values of $<0.05$ were considered statistically significant.

\section{Results}

\subsection{Nutritional Content}

The nutrient composition of the herbal products is given in Table 2. Protein was the major contributor of energy followed by carbohydrates and fat. The fat content of the herbal products was relatively low. HP 3 contained the highest level of fibre, followed by HP 2 and HP 1. HP 1 contained the highest mineral content $(11.71 \%)$ followed by HP $3(11.05 \%)$ and HP $2(7.73 \%)$. HP 2 contained the highest level of calcium (36.19 mg). HP 2 contained traces of lead (23ppm). However, no other heavy metals were evident in any of the products. Biochemical assays found caffeine in HP 1 (720 mg) and HP 3 (1203 mg).

Table 2. Quantity of nutrients in per $100 \mathrm{~g}$

\begin{tabular}{lccc}
\hline & \multicolumn{2}{c}{ Quantity of nutrients in per 100 g } \\
Chemical component & $\begin{array}{c}\text { Herbal } \\
\text { Product 1 }\end{array}$ & $\begin{array}{c}\text { Herbal } \\
\text { Product 2 }\end{array}$ & $\begin{array}{c}\text { Herbal } \\
\text { Product 3 }\end{array}$ \\
\hline Moisture (ml) & 3.23 & 4.29 & 5.49 \\
Energy (kcal) & 86.52 & 101.03 & 75.51 \\
Energy (kJ) & 362.24 & 422.99 & 316.15 \\
Protein (g) & 13.12 & 16.65 & 11.93 \\
Carbohydrate (g) & 6.62 & 7.88 & 5.75 \\
Fat (g) & 0.84 & 0.32 & 0.53 \\
Fibre (mg) & 1.02 & 1.29 & 1.36 \\
Mineral (g) & 11.71 & 7.73 & 11.05 \\
Calcium (mg) & 27.50 & 36.19 & 35.33 \\
Thiamine (mg) & 9.91 & 44.76 & 53.71 \\
Pyridoxine (mg) & 2.16 & 5.13 & 4.40 \\
Caffeine (mg) & 720 & 0 & 1203 \\
\hline
\end{tabular}

The herbal products lacked vitamin $\mathrm{C}$, nicotinamide and riboflavin. HP 3 contained the highest amount of thiamine (53.71 mg) followed by HP $2(44.76 \mathrm{mg})$, whereas HP 1 contained minimal amounts $(9.91 \mathrm{mg})$. HP 2 had the highest pyridoxine content $(5.13 \mathrm{mg})$ followed by HP 3 (4.40 mg) and HP 1 (2.16 mg).

\subsection{Contamination of the Herbal Products}

The microbiological assays indicated that all the herbal products studied contained less than 10 microbial counts (including total viable fungal count). None of the products contained weight-reducing medications such as orlistat, sibutramine or steroids.

\subsection{Effect of the Herbal Products onFood Intake and Weight}

The impact of the herbal products on food intake, body weight and internal organ weight is summarized in Table 3 (overleaf). No significant difference existed in food intake between the control and experimental groups. However, compared with the control group, significant changes in body weight occurred with $\mathrm{T} 1$ and $\mathrm{T} 3$; these preparations contained Senna acufolia (senna), Salvia officinalis (sage), Cuminum cyminum (cumin) and Zingiber officinale (ginger). 
Table 3. Effect of herbal products on food intake and changes in body and internal organ weight during the experimental period

\begin{tabular}{cccccccccc}
\hline Group & $\begin{array}{c}\text { Mean Food } \\
\text { Intake (g) }\end{array}$ & \multicolumn{2}{c}{ Mean change in body weight $(\mathrm{g})$} & \multicolumn{5}{c}{ Weight of internal organs(g/100 g body weight) } \\
& Pre -Treatment & Post-Treatment & Heart & Lungs & Liver & Spleen & Testis & Kidneys \\
\hline Control & $36.51 \pm 34.146$ & $319.69 \pm 24.41$ & $391.89 \pm 24.41$ & $1.50 \pm 0.04$ & $2.21 \pm 0.05$ & $13.97 \pm 0.35$ & $0.86 \pm 0.02$ & $1.96 \pm 0.05$ & $1.55 \pm 0.04$ \\
T1 & $32.96 \pm 43.644$ & $318.68 \pm 43.644$ & $328.96^{*} \pm 43.644$ & $1.57 \pm 0.04$ & $2.37 \pm 0.06$ & $13.42 \pm 0.41$ & $0.90 \pm 0.02$ & $1.98 \pm 0.05$ & $1.59 \pm 0.04$ \\
T2 & $38.96 \pm 34.146$ & $315.51 \pm 34.146$ & $398.96 \pm 34.146$ & $1.44 \pm 0.04$ & $2.17 \pm 0.05$ & $13.83 \pm 0.29$ & $0.82 \pm 0.01$ & $1.88 \pm 0.05$ & $1.53 \pm 0.04$ \\
T3 & $35.87 \pm 46.55$ & $315.65 \pm 46.55$ & $359.87^{*} \pm 46.55$ & $1.56 \pm 0.05$ & $2.43 \pm 0.06$ & $13.58 \pm 0.39$ & $0.88 \pm 0.02$ & $1.80 \pm 0.04$ & $1.59 \pm 0.04$ \\
\hline
\end{tabular}

Comparison between the experimental and control groups $* \mathrm{p}<0.05$ (student's t-test)

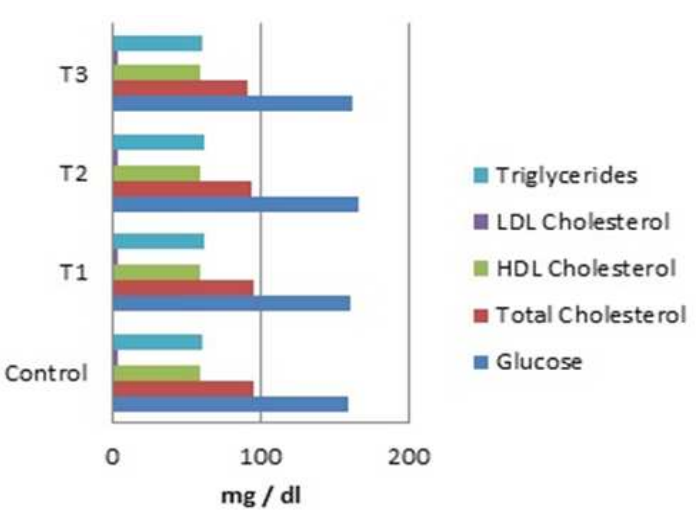

Figure 1. The effect of herbal products on the blood glucose and lipid profiles of the animal models. A comparison between the experimental and control groups. $H D L=$ high density lipoprotein; $L D L=$ low-density lipoprotein. *p $<0.05$ (student's t-test)

\subsection{Effect of the Herbal Products on the Metabolic and Physiological Parameters}

The impact of the herbal products on the haematological profiles is summarized in Table 4. The group fed with HP 2 had a slight increase in the WBC, RBC and $\mathrm{Hb}$; no other treatments resulted in significant changes.

There was no significant difference between the treatment and control groups in either lipid profile or blood glucose levels. Both Figure 1 and Figure 2 demonstrate that liver and kidney functions were within normal limits.

\section{Discussion}

The study found that herbal products containing senna,

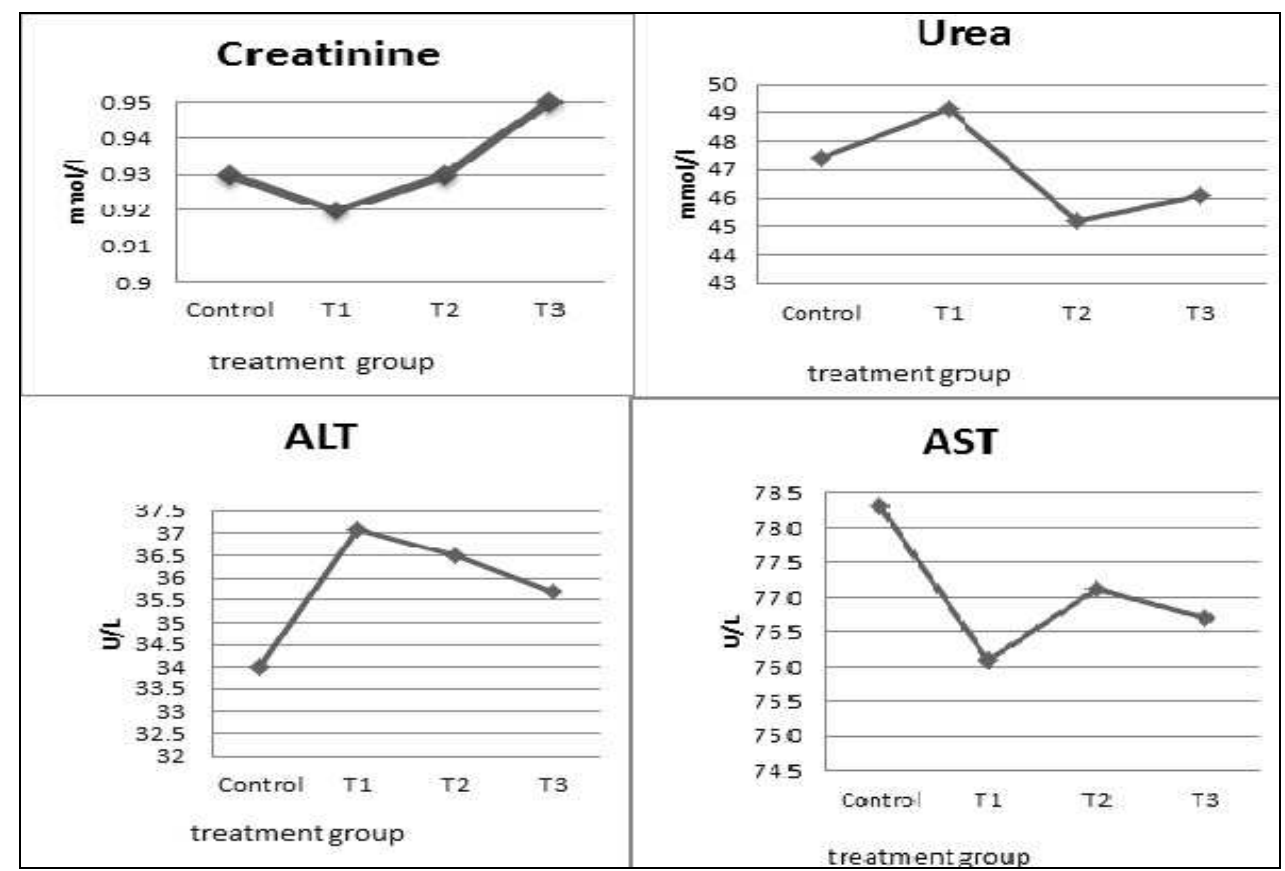

Figure 2. The effect of herbal mixtures on liver function. A comparison between the experimental and control groups. ALT = alanine aminotransferase; $A S T=$ aspartate aminotransferase. ${ }^{*} p<0.05$ (student's $t$-test) 
Table 4. Effect of herbal products on the metabolic and physiological parameters during the experimental period

\begin{tabular}{|c|c|c|c|c|c|}
\hline \multirow{2}{*}{ Treatment Group } & \multicolumn{5}{|c|}{ Haematological Variables } \\
\hline & WBC $\left(\times 10^{1 / / i t r e}\right)$ & RBC $\left(\times 10^{12} /\right.$ litre $)$ & Hb (g/dl) & $\operatorname{MCV}$ (fl) & HCT (\%) \\
\hline Control & $8.04 \pm 0.14$ & $9.18 \pm 0.16$ & $16.49 \pm 0.30$ & $51.01 \pm 0.91$ & $45.44 \pm 0.81$ \\
\hline Т 1 & $8.84 \pm 0.09$ & $9.77 \pm 0.17$ & $17.52 \pm 0.31$ & $51.52 \pm 0.92$ & $48.84 \pm 0.87$ \\
\hline Т 2 & $8.52 \pm 0.13$ & $10.10 \pm 0.18$ & $17.83 \pm 0.32$ & $51.32 \pm 0.92$ & $50.29 \pm 0.90$ \\
\hline T 3 & $8.12 \pm 0.20$ & $8.84 \pm 0.16$ & $16.08 \pm 0.29$ & $52.04 \pm 0.93$ & $44.62 \pm 0.80$ \\
\hline
\end{tabular}

Comparison between the experimental and control groups. $\mathrm{WBC}=$ white blood cell count; $\mathrm{RBC}=$ red blood cell count; $\mathrm{Hb}=$ haemoglobin, $\mathrm{HCT}=$ haematocrit; $\mathrm{MCV}=$ mean corpuscular volume. ${ }^{*} \mathrm{p}<0.05$ (student's t-test)

sage, cumin and ginger had weight reducing properties. Senna contains chemicals called sennosides, which irritate the lining of the bowel and decrease the transit time of the food through the gastrointestinal tract. Senna is an FDA approved non-prescription laxative.The general public sometimes uses senna for weight loss. Food intake and weight gain of the treatment groups using senna were less in comparison with the control group. Cumin and ginger have many proven nutraceutical properties including stomachic, diuretic, carminative, emmanogogic, antispasmodic, antimicrobial and hypoglycaemic properties [26]. Al Amin et al. [27] found that raw ginger possessed hypoglycaemic, hypocholesterolaemic and hypolipidaemic potential. Although the differences were not significant for the lipid profile and blood glucose levels, the present study supports this finding. These results suggest that the herbal products investigated may aid in managing obesity in humans. However, further studies using larger samples and on humans are necessary to confirm this conclusion.

The results of the chemical analysis for the herbal products found caffeine in HP $1(720 \mathrm{mg}$ per $100 \mathrm{~g})$ and HP 3 (1203 mg per $100 \mathrm{~g}$ ), which is known to decrease body weight in rodents $[28,29,30]$. These animal studies and the prospective epidemiologic studies on weight loss [31,32] suggest that long-term caffeine and coffee consumption could decrease body weight in humans though some evidence exists that caffeine's ability to increase thermogenesis, fat oxidation, metabolic rate and lipolysis and thereby to help persons lose weight is greater in non-obese than in obese people $[33,34,35,36]$. Furthermore, caffeine reportedly has a dose-response relationship: high caffeine levels have been proven to affect weight [37]. The high caffeine content per $100 \mathrm{~g}$ of the samples in this study, exceeded the International Food Information Council (IFIC) Foundation permissible limit by 500\% [38]. The Canadian Government's Guidelines to Healthy Eating recommend limiting caffeine intake to 400-450 mg per day [39]. Dependency on caffeine is characterized by the development of tolerance, as reflected by increases in dose size with time, persistent desire, and withdrawal symptoms [40]. This syndrome typically occurs only after ingestion of large amounts of caffeine, well over the amounts found in typical caffeinated beverages and caffeine tablets e.g. more than $400-500 \mathrm{mg}$ at a time. The symptoms of caffeine intoxication are comparable to the symptoms of an overdose and can cause anxiety, nervousness, sleep disturbance, irritability, agitation, and gastrointestinal disturbances [41]. Withdrawal symptoms include headaches, irritability, anxiety, depression, drowsiness, and fatigue.

This study also demonstrates the validity of the claim that these mixtures lead to a lower weight because two of the mixtures led to a decrease in weight which may be as a result of the high content of caffeine.

Table 2 shows that the protein content was high in the feeds. According to the labels of the health products, they were low in protein. The high amounts of protein added by mixing the herbal products with chow, most likely increased the feeling of fullness, and reduced the energy intake [42]. However, recent studies have concluded that the role of protein in weight reduction needs to be reassessed [43].

\section{Conclusions}

In conclusion, two of the herbal products resulted in a significant reduction in body weight compared with the control group. In contrast, weight and food intake non-significantly increased in another group. There were minimal or no significant differences in the haematological and biochemical profiles. Preparations that contained Senna acufolia (senna), Salvia officinalis (sage), Cuminum cyminum (cumin) and Zingiber officinale (ginger) had weight loss properties. It appears that herbal products may have benefit in managing obesity in human subjects. On the other hand, two of the herbal products content of caffeine was high which maybe caused the weight loss. The results of the study conclude that the mentioned claim does not comply with herbal content and it is necessary to ascertain that these mixtures do not contain compounds that have effects on the weight. Further studies are necessary on both animal and human subjects in order to confirm this finding.

\section{Acknowledgements}

The author thanks King Abdul-Aziz City for Science and Technology (KACST), Riyadh, KSA, for the financial assistance provided to conduct this research, as part of the research project (M-S 13-23). 


\section{References}

[1] World Health Organization "obesity and overweight". Fact sheet No. 311, 2012. Full Text.

[2] M. Al-Nozha,Y. Al-Mazrou, M.Al-Maatouq,M. Arafah, M. Khalil, N. Khan, Al-Marzouki, M. Abdullah, A.Al-Khadra, S.Al-Harthi, M. Al-Shahid, A. Al-Mobeireek, and M. Nouh, "Obesity in Saudi Arabia," Saudi Med J.26:824 - 829, 2005. Abstract

[3] R.L. Nahin, P.M. Barnes, B.J. Stussman, and B. Bloom, "Costs of complementary and alternative medicine (CAM) and frequency of visits to CAM practitioners: United States, 2007. Natl,” Health Stat. Report Jul 18, 1-14, 2009.

[4] M.J .Bogusz, M. Tufail, and H. Hassan, "How natural are 'natural herbal remedies'? A Saudi perspective. Adverse Drug React," Toxicol. Rev. 21, 219-229, 2002. Abstract

[5] S.M.K. Rates, "Plants as source of drugs," Toxicon, 39:603-613, 2001. Fall text

[6] M. J. CUPP, "Herbal Remedies: Adverse Effects and Drug Interactions," Am Fam Physician. 1;59(5):1239-1244.1999

[7] National Institutes of Health, "Meeting Report of the expert panel on weight loss," Bethesds. MD, USA, 1992. Full Text

[8] C.C. Chan, M.W. Koo, E.H. Ng, O.S. Tang, W.S. Yeung, and P.C. Ho, "Effects of Chinese Green Tea on Weight, and Hormonal and Biochemical Profiles in Obese Patients With Polycystic Ovary Syndrome-A Randomized Placebo-Controlled Trial," J Soc Gynecol Investig, Jan; 13(1):63-8, 2006.Abstract

[9] M.H. Pitter, K. Scmidt, and E. Ernst, "Adverse events of herbal food supplements for body weight reduction: systematic review," Obes Rev. 6:93-111, 2005. Full text.

[10] K.J. Steffen, J,L, Roerig, J.E. Mitchell, and R.D. Crosby, "Survey of herbal and alternative medication use among participants with eating disorder symptoms," Int J Eat Disord. Dec 39(8):741-6, 2006. Full Text.

[11] E.A. Al-Faris, N. Al-Rowais, A.G. Mohamed, M. O. Al-Rukban, A. Balla, M. A. Al-Noor, S. Al-Harby, and A .Sheikh, "Prevalence and pattern of alternative medicine use: the results of a household survey," Ann. Saudi Med. 28, 4-10, 2008. Abstract.

[12] A. Al-Majed, A. Al-Bekairi, M. Othman, A. Al-Shabanah, S. Abdulbasith, and A. Al-Yahia, "Studies on the toxicological, genotoxic, biochemical, endocrinological, pathological and reproductive toxicity evaluation of some herbal drugs marketed and used in The Kingdom of Saudi Arabia," Final Report, King Abdulaziz City For Science and Technology, General Directorate of Research Grants Programs Project No. (AR-21-41), 2006. Full text.

[13] AOAC. Official Method of Analysis of AOAC International. Association of Analytical Communities. 17th ed. Washington DC, USA. 2003

[14] WHO/PHARM. General recommendations for the preparation and use of Infrared spectra in pharmaceutical analysis. World Health Organization: Geneva 1992. Full Text.
[15] P.K. Chan, G.P. O'Hara, and A.W. Hayes, Principles and methods for acute and subchronic toxicity. In: Principles and Methods of Toxicology. New York: Raven Press, 1-52, 1982.

[16] A.T. Mossberg and A.W. Hayes, Subchronic toxicity testing. In: Hayes AW, ed. Principles and Methods of Toxicology 2nd ed. New York: Raven Press, 221-236, 1989.

[17] P.G. Reeves, F.H. Nielsen, and G.C. Fahey, “AIN-93 purified diets for laboratory rodents: final report of the American Institute Of Nutrition purified ad hoc writing committee on the reformulation of the AIN-76A rodent diet," Am Institute J Nutr. 153:1939-1951, 1993. Full Text.

[18] WHO Scientific Group. WHO. Procedures for investigating intentional and unintentional food additives. Tech Rep Ser. 348. (1967. Full Text.

[19] H.V. .Bergmeyer, G.N. Bowers, M..Horder, and A.W Mas, "Optimization of methods for aspartate aminotransferase and alanine amino transferase," Clin Chem Acta. 1978, 24:58-73, Full text.

[20] P. Trinder, "Determination of glucose in blood using glucose oxidase with an alternative oxygen acceptor," Ann Clin Biochem, 1969, 6:24-27, Full text.

[21] A. Tabacco, F. Meiattini, E. Moda, P. Tarli, "Simplified enzymatic/ colorimetric serum urea nitrogen determination (letter)," Clin Chem, 1979,25:336-337. Full Text.

[22] R.C. Rock, W.G. Walk, and D.C. Jennings, 1983, Nitrogen metabolites and renal function. In: Tietz NW, ed. Fundamentals of Clinical Chemistry 3rd ed. W.B. Saunders Company: Philadelphia, 679-684. Full Text.

[23] A.W. Wahlefeld. Determination of Serum Triglycerides Level In: Bergmeyer H [editor]: Methods of Enzymatic Analysis. Academic Press, New York, pp. 1831-1835, 1974.

[24] M. Nauck, D. Wiebe, and G.R. Warnick, Measurement of high-density-lipoprotein cholesterol. Rifai N Warnick GR Dominiczak MH eds. Handbook of lipoprotein testing. 2nd ed 2000:p 227-230, AACC Press Washington (DC).

[25] G.S. Rattiff, F. Hall, and H. Adams. Laboratory manual of clinical biochemistry. Scott and White. Memorial Hospital. Publication office, Timple, Tx, 1973.

[26] T. Allahghadri, I. Rasooli, P. Owlia, M.J. Nadooshan, T. Ghazanfari, M. Taghizadeh, and S.D. Astaneh, "Antimicrobial property, antioxidant capacity, and cytotoxicity of essential oil from cumin produced in Iran," J Food Sci.,2010,75: H54-H61. Full text.

[27] Z.M. Al-Amin, M. Thomson, K.K. Al-Qattan, R. Peltonen-Shalaby, and M. Ali, "Anti-diabetic and hypolipidaemic properties of ginger (Zingiber officinale) in streptozotocin-induced diabetic rats," 2006, Br J Nutr. 96(4):660-666. Full text.

[28] W.T. Cheung, C.M. Lee, and T.B. Ng, "Potentiation of the antioipolytic effect of 2-chloroadenosine after chronic caffeine treatment. Pharmacology," 1988,36:331-9. Abstract.

[29] K. Muroyama, S. Murosaki, Y. Yamamoto, H. Odaka, H.C. Chung, M. Miyoshi, "Anti-obesity effects of a mixture of thiamin, arginine, caffeine, and citric acid in non-insulin dependent diabetic KK mice, " 2003, Nutr Sci Vitaminol (Tokyo):49:56-63, Full text. 
[30] G. Zheng, K. Sayam, T. Okubo, L.R. Juneja, and I. Oguni, "Anti-obesity effects of three major components of green tea, catechins, caffeine and theanine in mice," In Vivo, 2004, 18:55-62. Full text.

[31] E. Lopez-Garcia, R.M. van Dam, S. Rajpathak, W.C. Willett, J.E. Manson, and F.B. Hu, "Changes in caffeine intake and long-term weight change in men and women," Am J Clin Nutr, 2006,83:674-80. Full text.

[32] R.M. van Dam, W.C. Willett, J.E. Manson, F.B. Hu, "Coffee, caffeine, and risk of type 2 diabetes: a prospective cohort study in younger and middle-aged U.S. women," Diabetes Care, 2006 29:398-403. Full text.

[33] H.J. Petrie, S.E. Chown, L.M. Belfie, A.M. Duncan, D.H. McLaren, J.A. Conquer, and T.E. Graham, "Caffeine ingestion increases the insulin response to an oral-glucose-tolerance test in obese men before and after weight loss," Am J Clin Nutr, 2004, 80:22-28. Full text.

[34] R.T. Jung, P.S. Shetty, W.P.T. James, M.A Barrand, and B.A. Callingha, "Caffeine: its effects on catecholamines and metabolism in lean and obese subjects," Clin Sci, 1981, 60:527-35, Full text.

[35] K.J. Acheson, B. .Zahorska-Markiewicz, K. Anantharaman, and E. Jequier, "Caffeine and coffee: their influence on metabolic rate and substrate utilization in normal weight and obese individuals," Am J Clin Nutr; 1980, 33:989-97. Full text.

[36] D. Bracco, J.M. Ferrarra, M.J. Arnaud, E. Jéquier, and Y. Schutz, "Effects of caffeine on energy metabolism, heart rate, and methylxanthine metabolism in lean and obese women," Am J Physiol, 1995, 269:E671-8. Abstract.
[37] M.S. Westerterp-Plantenga, M.P. Lejeune, and E.M. .Kovacs, "Body weight loss and weight maintenance in relation to habitual caffeine intake and green tea supplementation," Obes Res, 2005,13(7):1195-1204. Abstract.

[38] International Food Information Council (IFIC). IFIC Review: Caffeine and Health: Clarifying the Controversies. IFIC Foundation, 2008. Full text.

[39] Health Canada Food Program. Fact sheet-it's your health: caffeine. Ottawa, Canada: Health Canada, 2006 update 2010. Internet:

http://www.hc-sc.gc.ca/hl-vs/iyh-vsv/food-aliment/caffeineeng. php (accessed 8 November 2010).

[40] T.E. Graham, "Caffeine and exercise: metabolism, endurance and performance," Sports Med., 2001, 31:785-807. Full text.

[41] B.D. Smith and K. Tola. Caffeine: effects on psychological functioning and Performance. In: Spiller GA, ed. Caffeine. Boca Raton, FL .CRC Press, 278-9, 1998. Full Text.

[42] D. Weigle, P. Breen, C. Matthys "A high-protein diet induces sustained reductions in appetite, ad libitum caloric intake, and body weight despite compensatory changes in diurnal plasma leptin and ghrelin concentrations," Am J Clin Nutr, 2005, 82:41-48. Full Text.

[43] D. Paddon-Jones, E. Westman, R.D. Mattes, R.R. Wolfe, A. Astrup, and M. Westerterp-Plantenga, "Protein, weight management, and satiety," Am J Clin Nutr, 2008 87(5), 1558S-1561S. Full text. 